\title{
Investigating the Level of Knowledge of the Community about Oral and Dental Health
}

\author{
Sinem Birant $1, \odot$ Mine Koruyucu ${ }^{2}$ Hazal Ozcan ${ }^{2}$ Ceren llisulu ${ }^{3}$ Yelda Kasimoglu ${ }^{2}$ Nilufer Ustun ${ }^{4}$ \\ Simin Kocaaydin ${ }^{2}$ Dilara Bektas ${ }^{3}$ Gulsevim Usta ${ }^{3}$ Cansu Akay Tekin ${ }^{3} \quad$ Nural Bekiroglu ${ }^{5}$ Figen Seymen ${ }^{2}$
}

1Department of Pedodontics, Faculty of Dentistry, Istanbul

University-Cerrahpasa, Istanbul, Turkey

${ }^{2}$ Department of Pedodontics, Faculty of Dentistry, Istanbul

University, Istanbul, Turkey

3 Pediatric Dentist, Private Practice, Istanbul, Turkey

${ }^{4}$ Department of Pedodontics, Faculty of Dentistry, Istanbul Medipol

University, Istanbul, Turkey

5Department of Biostatistics, Medical School, Marmara University,

Istanbul, Turkey

Address for correspondence Sinem Birant, Department of Pedodontics, Faculty of Dentistry, Istanbul University - Cerrahpasa, Istanbul 34093, Turkey (e-mail: sinembirant@istanbul.edu.tr).

Eur J Dent:2021;5:145-151

\begin{abstract}
Keywords

- dental health

- behavior

- parents

- fluoride

- education

- oral health

Objectives This study aimed to determine the knowledge and approaches of the participants about oral and dental health.

Materials and Methods This was a questionnaire-based cross-sectional survey. Participants' demographic characteristics, tooth brushing habits, selection of toothpaste, and reasons for visiting the dentist were examined in this study. Participants' knowledge levels of fluoride and their attitudes toward the most common fluoride applications among preventive treatments were also evaluated. Data entry and analyses were performed using SPSS statistical software. Descriptive and inferential statistics and chi-square test were used for analyzes.

Results A total of 2,744 voluntary participants including 1,938 (70.6\%) females and 806 (29.4\%) males responded; 1,391 (50.7\%) participants know the contents of their toothpaste; 1,680 (61.2\%) participants point out that fluoride is effective in preventing dental caries. Female participants reported a statistically significant difference in their knowledge of what is fluoride when compared with male participants ( $p=$ 0.0001). The knowledge level of participants who had higher levels of education were statistically significantly different when compared with the participants who had lower education levels about fluoride and fluoride applications ( $p=0.0001)$.

Conclusions The results of this study indicate that participants' attitudes toward oral health and dental care need to be improved.
\end{abstract}

\section{Introduction}

Preservation and maintenance of oral and dental health are one of the most important factors affecting general health. It also plays a key role in quality of life..$^{1,2}$ The World Health Organization assesses the effects of various risk factors on health and emphasizes that these factors, which cause health status and worsen the quality of life, also adversely affect general health. ${ }^{3}$
Dental infections such as periodontal disease and tooth decay are the most common bacterial infections in children and adults. ${ }^{4}$ The major cause of tooth decay and gingival diseases is the dental plaque that accumulates on the tooth surfaces. ${ }^{5,6}$

Dental caries, the most common dental disease, causes pain, discomfort, and expensive treatment procedures in the community. ${ }^{7}$ In addition, these conditions are associated with stressful and unpleasant dental experiences between
DOI https://doi.org/ 10.1055/s-0040-1716583 ISSN 1305-7456.
C 2020 . European Journal of Dentistry.

This is an open access article published by Thieme under the terms of the Creative Commons Attribution-NonDerivative-NonCommercial-License, permitting copying and reproduction so long as the original work is given appropriate credit. Contents may not be used for commercial purposes, or adapted, remixed, transformed or built upon. (https://creativecommons.org/licenses/by-nc-nd/4.0/)

Thieme Medical and Scientific Publishers Pvt. Ltd., A-12, 2nd Floor, Sector 2, Noida-201301 UP, India 
children and adults. These negative factors are also affected by general health. Therefore, removal of the dental plaque and provision of oral hygiene in the prevention of tooth decay and periodontal diseases have a critical prescription. ${ }^{8}$

Epidemiological studies show that tooth decay rates can be successfully controlled by improving oral hygiene. ${ }^{9}$ Oral and dental health care programs are the most basic and effective for the protection and maintenance of dental health among children and adults. From these practices, individual practices are at the forefront of improving the oral and dental health of the community and reducing the prevalence of dental diseases. ${ }^{10,11}$

The individual oral hygiene habits such as tooth brushing habits that are used to protect oral and dental health can vary depending on the level of knowledge of the community on oral health. ${ }^{12}$ That is, the level of knowledge about oral and dental health of individuals also affects their attitudes toward hygiene habits on oral and dental health. Also, the attitudes and skills of parents about oral hygiene affect the prevalence of oral and dental diseases as well as the development of oral hygiene habits of children. ${ }^{13,14}$ The aim of this study is to investigate the level of knowledge about fluoride and fluoride applications among the professional dental practices as well as knowledge, attitudes, and behaviors about oral and dental health.

\section{Materials and Methods}

This cross-sectional study was completed compatible with the Declaration of Helsinki presented in 1975 which is revised in 2000. Ethical approval of the study protocol was obtained from the Research Ethical Board of Faculty of Dentistry, Istanbul University, Istanbul, Turkey (No: 2016/63).

The study population comprised 2,744 randomly selected volunteered people ranging in age 18 to 51 years and older. The exclusion criteria were questionnaires that individuals had not completed, for whatever reason. All participants were asked to answer a total of 22 questions, including subgroups. A questionnaire was developed to assess participants' dental health knowledge, oral health experiences, and preferences and provided information on their demographic characteristics. Participants' knowledge levels of fluoride and their attitudes toward the most common fluoride applications among preventive treatments were also evaluated.

\section{Data Measurements}

\section{Participant Demographics}

The distribution of basic demographic information including participants' age, gender, education level, working status, monthly income, and participants having children were evaluated.

\section{Knowledge and Attitude of Oral Hygiene Habits for Participants and Their Children}

The following five-item scale to assess participants' oral health knowledge and attitude was designed. These five questions werealso evaluated for their children by the participants who have children. The items included: (1) How often do you brush your teeth? (2) Which features does toothpaste have, when you are choosing toothpaste? (3) What brand of toothpaste are you using? (4) Do you know the contents of your toothpaste? (5) Why did you go to your dentist in the last year?

\section{Knowledge and Attitude of Fluoride Applications}

Knowledge and attitude of fluoride applications consisted of eight items were evaluated: (1) Do you know what the fluoride is? (2) Does the fluoride help prevent tooth decay? (3) What is the amount of toothpaste for children younger than 3 years? (4) What is the amount of toothpaste for children aged 3 to 6 years? (5) What is the amount of toothpaste for children of 6 years and older? (6) Do you know professional fluoride applications? (7) Have you ever had topical fluoride application? (8) Do you know systemic fluoride applications?

\section{Statistical Analysis}

Collected data were processed statistically using SPSS. Descriptive statistics (frequencies, standard deviations, means, ranges, and proportions) were used to summarize the data. Differences in knowledge and attitudes about oral health based on participants' demographic characteristics were analyzed with chi-square test. Results were reported as statistically significant at $p<0.005$.

\section{Results}

\section{Demographic Features of the Participants}

- Table 1 shows the demographic information of the 2,744 participants in the survey; 1,938 of participants were females (70.6\%) and 806 were males (29.4\%). The age prevalence ranged from $11.9 \%$ (329) at age 18 to 25 years, $32.6 \%$

Table 1 Demographic data of the participants

\begin{tabular}{|c|c|c|}
\hline & $N$ & $\%$ \\
\hline \multicolumn{3}{|l|}{ Gender } \\
\hline Female & 1,938 & 70.6 \\
\hline Male & 806 & 29.3 \\
\hline \multicolumn{3}{|l|}{ Age } \\
\hline $18-25$ & 329 & 11.9 \\
\hline $26-35$ & 896 & 32.6 \\
\hline $36-50$ & 1,330 & 48.4 \\
\hline $50+$ & 189 & 6.8 \\
\hline \multicolumn{3}{|c|}{ Education level } \\
\hline Primary & 372 & 13.5 \\
\hline Middle & 361 & 13.1 \\
\hline High & 973 & 35.4 \\
\hline University & 1,038 & 37.8 \\
\hline \multicolumn{3}{|c|}{ Working situation } \\
\hline Yes & 1,333 & 48.5 \\
\hline No & 1,411 & 51.4 \\
\hline \multicolumn{3}{|l|}{ Income level } \\
\hline Low & 860 & 31.3 \\
\hline High & 1,884 & 68.6 \\
\hline \multicolumn{3}{|c|}{ Having children } \\
\hline Yes & 2,157 & 78.6 \\
\hline No & 587 & 21.3 \\
\hline
\end{tabular}


(896) at age 26 to 35 years, $48.4 \%(1,330)$ at age 36 to 50 years to $6.8 \%(189)$ at 51 years and older. While the education levels of the participants were evaluating, the four education groups were used to determine participants' educational levels. According to these scales, $13.5 \%$ of them were graduated from primary school, $13.1 \%$ from middle school, $35.4 \%$ from high school, and $37.8 \%$ were university graduates. Total $48.5 \%$ $(1,333)$ of the participants were working, while $51.4 \%$ (1411) were not. It was also found that $31.3 \%$ of the participants had a low income level. It was reported that 78.6 of the participants had children.

\section{Knowledge and Attitude of Oral Hygiene Behaviors}

Approximately $53 \%$ of the study population reported that they brushed their teeth twice a day. While $37 \%$ of the study population stated that they brushed their teeth once a day, $8 \%$ of the population gave the answer "a few times in a week," and 3\% of them said that they brushed their teeth less frequently. Total $43 \%$ of the parents said that they brushed their teeth two or more times a day for their children. Similarly, $43 \%$ of the parents stated that their children brushed their teeth once a day; 12 and $2 \%$ of the parents gave the answers "a few times in a week" and "less frequently." According to the results of the study, the most important factor affecting the participants' toothpaste is the brand of toothpaste (35.3\%). Another important factor is the dentist's recommendation (35.7\%). The participants stated that dentist's recommendation was the most important factor in selecting children's toothpaste (41.7\%).

Many subjects (44\%) reported that they visited the dentist only when they felt pain or had a problem with the tooth during the last year. Only $24 \%$ of the study population reported that they visited the dentist only for examination and routine checkup. About $44 \%$ of the study population never visited a dentist in the last year.

Total $43 \%$ of the parents reported that they had taken their children to the dentist with dental problems, while $25 \%$ of them stated that they had taken for the routine checkup and $42 \%$ of them stated that they had not taken their children to the dentist in the last 1 year. The reason for going to the dentist and the level of income were also compared. Participants with a high level of income seem to have a statistically significant level of dental control over the past year according to the participants who have low income $(p=0.001)$. The participants with lower income levels stated that they went to the dentist with more dental problems or they did not go at all in 1 year.

\section{Knowledge and Attitude of Oral Hygiene Habits and Fluoride Applications}

Participants' knowledge of oral and dental health and preventive dentistry applications are shown in -Table 2 . Approximately $52.1 \%$ of respondents realized the contents of their toothpastes and also $40 \%$ of the childbearing participants reported that they realized the contents of the child toothpastes. While more than half of the participants ( $n=1,744 ; 63.5 \%$ ) had knowledge about the fluoride, very few of the participants knew the professional topical fluoride
Table 2 Knowledge levels of the participants

\begin{tabular}{|c|c|c|}
\hline & $N$ & $\%$ \\
\hline \multicolumn{3}{|c|}{ Do you know the contents of your toothpaste? } \\
\hline Yes & 1,430 & 52.1 \\
\hline No & 1,314 & 47.8 \\
\hline \multicolumn{3}{|c|}{ Do you know the contents of the toothpaste for your child? } \\
\hline Yes & 1,191 & 43.4 \\
\hline No & 885 & 32.3 \\
\hline \multicolumn{3}{|c|}{ Do you know what the fluoride is? } \\
\hline Yes & 1,744 & 63.5 \\
\hline No & 1,000 & 36.4 \\
\hline \multicolumn{3}{|c|}{ Does the fluoride help prevent the tooth decays? } \\
\hline Yes & 1,795 & 65.4 \\
\hline No & 821 & 29.9 \\
\hline I do not know & 128 & 4.6 \\
\hline \multicolumn{3}{|c|}{ Do you know the professional topical fluoride applications? } \\
\hline Yes & 331 & 12.06 \\
\hline No & 2,413 & 87.9 \\
\hline \multicolumn{3}{|c|}{ Do you know the systemic fluoride applications? } \\
\hline Yes & 514 & 18.7 \\
\hline No & 2,230 & 81.2 \\
\hline
\end{tabular}

application $(n=331 ; 12.06 \%)$ and systemic fluoride applications ( $n=514 ; 18.7 \%$ ). Total $65.4 \%$ of respondents answered "yes," $29.1 \%$ answered "no," and $4.6 \%$ answered "I do not know" to the question that "Does fluoride help prevent tooth decays?" A total of $66.5 \%$ of respondents answered correctly what amount of toothpaste should be for children younger than 3 years. The percentage of participants who know the amount of toothpaste correctly for children aged 3 to 6 years is $23.2 \%$. The amount of toothpaste for children older than 6 years was correctly known by $61.5 \%$ of the participants.

The demographic data and oral hygiene habits are statistically compared in - Table 3 . Statistical analysis of the data obtained showed that the frequency of teeth brushing was significantly higher for women than for men $(p=0.001)$. As age increases, there is a significant decrease in the frequency of tooth brushing $(p=0.001)$. Participants with a high level of education have significantly more tooth brushing per day $(p=0.001)$. A statistically significant difference was not found between working and nonworking participants, in terms of tooth brushing frequency $(p=0.077$ ). Compared with the income levels of the participants, the participants with high income levels had a significantly higher frequency of tooth brushing $(p=0.001)$.

In comparison between genders, it was found that women had significantly more knowledge about fluoride $(p=0.0001)$. The results are shown in - Table 4 . The question that "Do you know the professional topical fluoride treatments?" was answered "yes" by $25 \%$ of the females and $18.6 \%$ of the males, and it was found that women had more knowledge at a statistically significant rate than men $(p=0.0001)(-$ Table 4). 
Table 3 Comparison of demographic data and tooth brushing frequency

\begin{tabular}{|c|c|c|c|c|c|}
\hline & $\begin{array}{l}\text { Twice or more a } \\
\text { day }\end{array}$ & Once a day & Few in a week & Less frequently & $p$-Value \\
\hline \multicolumn{6}{|l|}{ Gender } \\
\hline Female & $60.2 \%$ & $34.2 \%$ & $4.7 \%$ & $0.8 \%$ & \multirow[t]{2}{*}{0.001} \\
\hline Male & $36.4 \%$ & $44.4 \%$ & $14.1 \%$ & $5.1 \%$ & \\
\hline \multicolumn{6}{|l|}{ Age } \\
\hline $18-24$ & $60.9 \%$ & $32.1 \%$ & $7.1 \%$ & $0.0 \%$ & \multirow[t]{4}{*}{0.001} \\
\hline $25-35$ & $54.7 \%$ & $35.2 \%$ & $7.1 \%$ & $3 \%$ & \\
\hline $36-50$ & $52.6 \%$ & $38.9 \%$ & $6.9 \%$ & $1.6 \%$ & \\
\hline $50+$ & $38.5 \%$ & $43.7 \%$ & $13.2 \%$ & $4.6 \%$ & \\
\hline \multicolumn{6}{|l|}{ Education level } \\
\hline Primary & $41.4 \%$ & $41.7 \%$ & $12.1 \%$ & $4.8 \%$ & \multirow[t]{4}{*}{0.001} \\
\hline Middle & $35.8 \%$ & $44.8 \%$ & $15.7 \%$ & $3.8 \%$ & \\
\hline High & $50 \%$ & $42.2 \%$ & $5.8 \%$ & $2 \%$ & \\
\hline University & $66.6 \%$ & $28.4 \%$ & $0.4 \%$ & $0.4 \%$ & \\
\hline \multicolumn{6}{|c|}{ Working situation } \\
\hline Yes & $55.6 \%$ & $34.6 \%$ & $7.6 \%$ & $2.2 \%$ & \multirow[t]{2}{*}{0.077} \\
\hline No & $51.5 \%$ & $39.4 \%$ & $7.1 \%$ & $1.9 \%$ & \\
\hline \multicolumn{6}{|l|}{ Income level } \\
\hline Low income & $46.0 \%$ & $37.7 \%$ & $12.3 \%$ & $4 \%$ & \multirow[t]{2}{*}{0.001} \\
\hline High income & $56.4 \%$ & $36.8 \%$ & $5.5 \%$ & $1.2 \%$ & \\
\hline
\end{tabular}

Table 4 Comparison of the gender and knowledge of the fluoride

\begin{tabular}{|c|c|c|c|}
\hline & Female (\%) & Male (\%) & $p$-Value \\
\hline \multicolumn{4}{|c|}{ Do you know the fluoride? } \\
\hline Yes & 67.5 & 55.5 & \multirow[t]{2}{*}{0.0001} \\
\hline No & 32.5 & 44.5 & \\
\hline \multicolumn{4}{|c|}{ Do you know the professional topical fluoride applications? } \\
\hline Yes & 25 & 18.6 & \multirow[t]{2}{*}{0.001} \\
\hline No & 75 & 81.4 & \\
\hline
\end{tabular}

As the age of participants increases, the knowledge level of fluoride is significantly increased ( $p=0.0001)$, but the knowledge level of fluoride in participants aged 51 years and older is the lowest.

- Table 5 shows the relationship between educational level and fluoride knowledge. According to the comparison between the education levels, fluoride knowledge levels of the participants with higher education level were found to be significantly higher $(p=0.0001)$ (- Table 5).

The fluoride knowledge levels of participants who had previously applied topical fluoride (fluoride varnish or gel) were found to be statistically significantly higher than those who did not have topical fluoride experience $(p=0.001)$ (-Table 6).

The participants who were at work were found to have a statistically significant higher level of knowledge about "What is the fluoride?" and "professional fluoride applications" than the participants who did not work $(p=0.003$; $p=0.0001)$.
Participants have found that those who use social media as a source of fluoride information have less knowledge of fluoride $(p=0.014)$.

\section{Discussion}

The importance of studies involving the knowledge and behavior of the population on oral and dental health is increasing. Poor oral hygiene is often described as the most important local etiologic factor of the dental diseases. ${ }^{15}$

The public oral health is related to their oral health information because the habits related to oral health are shaped by the individual's level of knowledge. ${ }^{16}$

In addition, parents' knowledge and habits of oral and dental health play an important role in the development of oral hygiene habits of children. ${ }^{17}$ Therefore, the knowledge and awareness are very important prerequisites for changes in behaviors of the community related to health and disease prevention. ${ }^{18}$ 
Table 5 Comparison of the educational levels and knowledge of the fluoride

\begin{tabular}{|c|l|l|l|l|l|l|}
\hline \multicolumn{2}{|l|}{} & Primary & Middle & High & University & $p$-Value \\
\hline Do you know the fluoride? & $35.5 \%$ & $45 \%$ & $64.2 \%$ & $80.4 \%$ & 0.0001 \\
\hline Yes & $64.5 \%$ & $55 \%$ & $35.8 \%$ & $19.6 \%$ & 0.0001 \\
\hline No & \multicolumn{5}{|l|}{} \\
\hline Does the fluoride help prevent the tooth decays? & $62 \%$ & $62.5 \%$ & $70.8 \%$ & $74.1 \%$ & $25.1 \%$ \\
\hline Yes & $37.7 \%$ & $37.5 \%$ & $28.8 \%$ & \\
\hline No & $11 \%$ & $10.7 \%$ & $21.6 \%$ & $32.6 \%$ \\
\hline Do you know the topical fluoride applications? & $89 \%$ & $89.3 \%$ & $78.4 \%$ & $67.4 \%$ \\
\hline Yes
\end{tabular}

Table 6 Comparison of the fluoride knowledge level with experience about topical fluoride applications

\begin{tabular}{|c|c|c|c|}
\hline & Experience $(+)$ & Experience (-) & $p$-Value \\
\hline \multicolumn{4}{|c|}{ Do you know the fluoride? } \\
\hline Yes & $13.1 \%$ & $4.7 \%$ & \multirow[t]{2}{*}{0.001} \\
\hline No & $86.9 \%$ & $95.3 \%$ & \\
\hline \multicolumn{4}{|c|}{ Does the fluoride help prevent the tooth decays? } \\
\hline Yes & $12.6 \%$ & $5.5 \%$ & \multirow[t]{2}{*}{0.001} \\
\hline No & $87.4 \%$ & $94.5 \%$ & \\
\hline \multicolumn{4}{|c|}{ Do you know the topical fluoride applications? } \\
\hline Yes & $27.7 \%$ & $4.7 \%$ & \multirow[t]{2}{*}{0.001} \\
\hline No & $72.3 \%$ & $95.3 \%$ & \\
\hline
\end{tabular}

The knowledge and attitudes of the population on oral and dental health were determined and the awareness of the community was important in line with the identified deficiencies. Many previous studies show that oral hygiene habits and oral health information are related to demographic characteristics. ${ }^{19,20}$

Rajab et al reported that the parents who have high level of education cared more about their children's and their oral health. ${ }^{20}$ In our study, there was also a significant relationship between oral and dental health habits and education levels $(p=0.000)$. Some studies have emphasized that lowsocioeconomic status people visit a dentist more frequently due to pain or discomfort. ${ }^{17,21,22}$ This is confirmed by the finding of our study as well. In this study, a direct relationship was found between socioeconomic level and tooth brushing frequency ( $p=0.001)$. Similar to the findings in other surveys, study subjects with a higher socioeconomic status practiced better oral hygiene. ${ }^{23,24}$

Ota et al have investigated the relationship between fluoride toothpaste and toothpaste selection in their work of $\sim 6,000$ people. They have found that the most important factor in the selection of toothpaste is taste. In addition, the community has reached the conclusion that fluoride-free toothpastes are preferred because of the lack of information on fluoride. ${ }^{25}$ In our study, it was reported that, unlike the results of this study, the most important factor affecting toothpaste choice for adults was the brand of the toothpaste and for the children, it was the dentist's recommendation. The taste factor affects $\sim 4$ to $5 \%$ of participants. The presence of fluoride in toothpastes also affects 14 to $12 \%$ of toothpaste choice for adults and their children, respectively.

The level of information about the oral health of the community and in this survey, the identification of oral hygiene habits, as opposed to further level of information about the community's preventive dental care from this type of work done in Turkey was also investigated. The results showed that most of the participants had a low level of knowledge about professional topical fluoride applications (12.06\%) and systemic fluoride applications (18.7\%). This level of knowledge in similar studies has been reported as more than $50 \%$ of relevant results. ${ }^{26,27}$

Tahani et al assessed the knowledge level of the community on professional fluoride applications. The results obtained did not reveal any significant difference between age, gender, and level of knowledge. However, they found a statistically significant difference between the education levels and the treatment experiences and the knowledge level. ${ }^{28}$

Blumer et al reported that there was no significant difference in age, dental experience, and level of education between having information about preventive dental treatments in their survey study. ${ }^{29}$ 
In our study, the knowledge of topical fluoride applications was found more in women than in men; a similar trend has been reported in the findings of study conducted by Jagan et al. ${ }^{30}$ Also, statistically significant difference was found between the education levels, the treatment experiences, and the knowledge levels of the participants. There was no statistically significant difference between the age level and the level of knowledge as in other studies ${ }^{31,32}$ but in contrast with the findings of the study conducted by Jagan et al. ${ }^{30}$

Those who use social media as a source of information, from participants, have found that the level of knowledge about what fluoride is less than participants who do not use social media as a source of information. In other studies, the majority of parents have learned about preventive dental treatment with mass media, but it is reported that dental surgeons have better knowledge. This result has been associated with face-to-face training with dentists. 27,32,33

\section{Consclusions}

Due to the low knowledge of participants about professional preventive dental care, it is necessary to improve the collective consciousness to improve the oral health of children and community. On the contrary, owing to the positive impact of the trainings provided by the dentists and mass media, it appears that increasing the knowledge of dentists in this area and asking them to offer prevention education to their patients while providing services as well as involving the mass media in providing public education can be effective strategies to raise the knowledge of society in making use of oral health preventive measures.

\section{Limitations}

The present study had some limitations. The results may not reflect the knowledge and attitudes of the participants. Data reported in this study is based on self-reported information of participants in different region, so this limits the ability to determine the actual prevalence of oral health knowledge. Socially desirable answers to the questions regarding the participants' own oral health knowledge and their children's dental care may have biased the study results.

\section{Note}

This research was presented at the 1 st International Congress of Preventive Dentistry March 5-8, 2018, Erzurum, Turkey as an oral presentation.

\section{Conflict of Interest}

None declared.

\section{References}

1 Hamissi J, Bakianian Vaziri P, Davalloo A. Evaluating oral hygiene knowledge and attitude of pregnant women. Iran J Public Health 2010;39(1):28-31

2 Petersen PE. Sociobehavioural risk factors in dental caries international perspectives. Community Dent Oral Epidemiol 2005;33(4):274-279

3 Saldūnaitė K, Bendoraitienė EA, Slabšinskienė E, Vasiliauskienè I, Andruškevičienė V, Zūbienė J. The role of parental education and socioeconomic status in dental caries prevention among Lithuanian children. Medicina (Kaunas) 2014;50(3):156-161

4 Das UM, Beena JP, Azher U. Oral health status of 6- and 12-year-old school going children in Bangalore city: an epidemiological study. J Indian Soc Pedod Prev Dent 2009;27(1):6-8

5 Prasanth M. Antimicrobial efficacy of different toothpastes and mouthrinses: an in vitro study. Dent Res J (Isfahan) 2011;8(2):85-94

6 Sadeghi M, Assar S. An in vitro antimicrobial activity of ten Iranian-made toothpastes. Dent Res J (Isfahan) 2009; $6(2): 87-92$

7 Longbottom C, Ekstrand K, Zero D. Traditional preventive treatment options. Monogr Oral Sci 2009;21:149-155

8 Nakonieczna-Rudnicka M, Bachanek T, Strycharz-Dudziak M, Kobyłecka E. Oral hygiene habits among tobacco-smoking and non-smoking students of the Medical University of Lublinchosen aspects [in Polish]. Przegl Lek 2010;67(10):871-874

9 Bruno-Ambrosius K, Swanholm G, Twetman S. Eating habits, smoking and toothbrushing in relation to dental caries: a 3-year study in Swedish female teenagers. Int J Paediatr Dent 2005;15(3):190-196

10 Fine DH, Furgang D, Markowitz K. Sreenivasan PK, Klimpel K, De Vizio W. The antimicrobial effect of a triclosan/copolymer dentifrice on oral microorganisms in vivo. J Am Dent Assoc 2006;137(10):1406-1413

11 Ozaki F, Pannuti CM, Imbronito AV, et al. Efficacy of a herbal toothpaste on patients with established gingivitis-a randomized controlled trial. Braz Oral Res 2006;20(2):172-177

12 Al-Omiri MK, Al-Wahadni AM, Saeed KN. Oral health attitudes, knowledge, and behavior among school children in North Jordan. J Dent Educ 2006;70(2):179-187

13 Sheiham A, Bonecker M, Promoting Children's Oral Health: Theory and Practice. Brazil: Quintessence; 2006:191

14 Vanagas G, Milasauskiene Z, Grabauskas V, Mickeviciene A. Associations between parental skills and their attitudes toward importance to develop good oral hygiene skills in their children. Medicina (Kaunas) 2009;45(9):718-723

15 Kulak-Ozkan Y, Kazazoğlu E, Arikan A. Oral hygiene habits, denture cleanliness, presence of yeasts and stomatitis in elderly people. J Oral Rehabil 2002;29(3):300-304

16 Suresh BS, Ravishankar TL, Chaitra TR, Mohapatra AK, Gupta V. Mother's knowledge about pre-school child's oral health. J Indian Soc Pedod Prev Dent 2010;28(4):282-287

17 Jürgensen $\mathrm{N}$, Petersen $\mathrm{PE}$. Oral health and the impact of socio-behavioural factors in a cross sectional survey of 12-year old school children in Laos. BMC Oral Health 2009;9:29

18 Gussy MG, Waters EB, Riggs EM, Lo SK, Kilpatrick NM. Parental knowledge, beliefs and behaviours for oral health of toddlers residing in rural Victoria. Aust Dent J 2008;53(1):52-60

19 Lin HC, Wong MC, Wang ZJ, Lo EC. Oral health knowledge, attitudes, and practices of Chinese adults. J Dent Res 2001;80(5):1466-1470

20 Rajab LD, Petersen PE, Bakaeen G, Hamdan MA. Oral health behaviour of schoolchildren and parents in Jordan. Int J Paediatr Dent 2002;12(3):168-176

21 Ayele FA, Taye BW, Ayele TA, Gelaye KA.. Predictors of dental caries among children 7-14 years old in Northwest Ethiopia: a community based cross-sectional study. BMC Oral Health 2013;13-7

22 Hamasha AA, Warren JJ, Levy SM, Broffitt B, Kanellis MJ. Oral health behaviors of children in low and high socioeconomic status families. Pediatr Dent 2006;28(4):310-315

23 Esa R, Razak IA, Jallaudin RL, Jaafar N. A survey on oral hygiene practices among Malaysian adults. Clin Prev Dent 1992;14(1):23-27

24 Ronis DL, Lang WP, Farghaly MM, Passow E. Tooth brushing, flossing, and preventive dental visits by Detroit-area residents 
in relation to demographic and socioeconomic factors. J Public Health Dent 1993;53(3):138-145

25 Ota J, Yamamoto T, Ando Y, Aida J, Hirata Y, Arai S. Dental health behavior of parents of children using non-fluoride toothpaste: A cross-sectional study. BMC Oral Health 2013;13:74

26 Baradaran Nakhjavani Y. Mothers knowledge about fluoride therapy and fissure sealants. J Oral Health Oral Epidemiol 2013; $2: 1-5$

27 MafeniJO, Messer LB. Parental knowledge and attitudes towards pit and fissure sealants. Aust Dent J 1994;39(3):172-180

28 Tahani B, Yadegarfar G, Ahmadi A. Knowledge, attitude, and practice of parents of 7-12-year-old children regarding fissure sealant therapy and professional fluoride therapy. J Educ Health Promot 2017;6:106

29 Blumer S, Ratson T, Peretz B, Dagon N. Parents' attitude towards the use of fluorides and fissure sealants and its effect on their children's oral health. J Clin Pediatr Dent 2018;42(1):6-10
30 Jagan P, Fareed N, Battur H, Khanagar S, Manohar B. Conceptual knowledge of oral health among school teachers in South India, India. Eur J Dent 2018;12(1):43-48

31 Mohammadi TM, Malekmohammadi M, Hajizamani HR, Mahani SA. Oral health literacy and its determinants among adults in Southeast Iran. Eur J Dent 2018;12(3):439-442

32 Mårtensson C, Söderfeldt B, Andersson P, Halling A, Renvert S. Factors behind change in knowledge after a mass media campaign targeting periodontitis. Int J Dent Hyg 2006;4(1):8-14

33 Gholami M, Pakdaman A, Montazeri A, Jafari A, Virtanen JI. Assessment of periodontal knowledge following a mass media oral health promotion campaign: a population-based study. BMC Oral Health 2014;14:31 